\title{
Decompressive Craniectomy for Severe Traumatic Brain Injury: A Review of its Current Status
}

\section{Honeybul $\mathbf{S}^{*}$}

Department of Neurosurgery, Sir Charles Gairdner Hospital and Royal Perth Hospital, Western Australia

\begin{abstract}
Over the past two decades there has been a resurgence of interest in the use of decompressive craniectomy in the management of severe traumatic brain injury. A number of retrospective studies have demonstrated that in the context of intractable intracranial hypertension surgical decompression can lower the intracranial pressure and a significant number of patients make a good long term recovery. It has been generally assumed that by lowering the intracranial pressure not only are patients more likely to survive but outcome is also improved. However a recent trial has demonstrated that this is not necessarily the case. The DECRA study compared early decompressive craniectomy with standard medical therapy and the results were that there were more unfavourable outcomes in the patients in the surgical arm of the trial. Whilst there were some problems with randomisation and crossover of patients from the standard therapy to the medical arm, overall the trial has provided the first class I evidence in adult neurotrauma and should have been heralded as a landmark study. Unfortunately this has not been the case and commentary on the trial has in most cases been somewhat critical. This review examines the trial in detail and outlines the current role and future direction of decompressive craniectomy in the management of severe traumatic brain injury.
\end{abstract}

Keywords: Traumatic brain injury; Decompressive craniectomy

\section{Introduction}

Over the past two decades there has been a resurgence of interest in the use of decompressive craniectomy in the management of severe traumatic brain injury (TBI) [1-4]. The procedure is technically straightforward and can be performed either unilaterally or bilaterally (or bifrontally). A unilateral decompression is usually performed following evacuation of a mass lesion such as a subdural haematoma or when the cerebral swelling is localized to one hemisphere. A bilateral or bifrontal craniectomy is usually performed when there is diffuse cerebral swelling.

The rationale for surgical decompression is based on the strong association between elevated intracranial pressures and poor outcome and mortality following TBI $[5,6]$. By providing additional space into which the injured brain can expand the intracranial pressure is lowered and it has been assumed that not only are patients more likely to survive, but also outcome is improved.

Unfortunately this assumption has been seriously questioned by the results of a recently published trial comparing early decompressive surgery with standard medical therapy in which the authors concluded that decompressive craniectomy was associated with more unfavourable outcomes [7]. The aim of this review is to examine these findings in more detail and review the current role of decompressive craniectomy in the management of severe TBI.

\section{The History of Decompressive Craniectomy}

The procedure was first described in 1894 by Annandale and its use gained popularity in the early 1970's only to subsequently fall into disrepute due to poor clinical outcomes [8,9]. At the same time experimental studies suggested that decompression may actually worsen cerebral oedema and this led to use of the procedure being almost abandoned [10].

However, throughout the 1980 's its popularity returned. A number of studies demonstrated that in the context of intractable intracranial hypertension, surgical decompression could reliably lower the intracranial pressure not only following severe TBI but also following ischemic stroke [11-13], subarachnoid haemorrhage [14,15] and cases of severe intracranial infection [16-19]. In addition to these promising clinical results, experimental data suggested that cerebral oedema and secondary brain injury may be reduced following early decompression and whilst this may involve a number of independent, factors a significant contribution comes may be due to maintenance of cerebral perfusion [20,21].

\section{The Physiological Rationale for Decompressive Craniectomy}

In 1783 Monroe J [22] deduced that the cranium was a "rigid box" filled with a "nearly incompressible brain" and that its total volume tends to remain constant (Figure 1). The doctrine states that any increase in the volume of the cranial contents (e.g. brain, blood or cerebrospinal fluid), will elevate intracranial pressure. Furthermore, if one of these three elements increases in volume, it must occur at the expense of volume of the other two elements. In 1824 Kellie [23] confirmed many of Monro's early observations. When the brain is injured and starts to swell or there is a mass lesion such as an intracerebral haematoma, the compensation is made at the expense of blood and CSF volume (Figure 2). As the brain becomes progressively more swollen or a mass lesion increases in size these compensatory mechanisms become exhausted and for incrementally smaller increases in volume there are progressively greater increases in pressure (Figure 3 ). When viewed

*Corresponding author: Honeybul S, Consultant Neurosurgeon, Department of Neurosurgery, Sir Charles Gairdner Hospital and Royal Perth Hospital, Western Australia, Fax: 089346 3824; E-mail: stephen.honeybul@health.wa.gov.au

Received February 17, 2012; Accepted March 02, 2012; Published March 07, 2012

Citation: Honeybul S (2012) Decompressive Craniectomy for Severe Traumatic Brain Injury: A Review of its Current Status. J Neurol Neurophysiol S9. doi:10.4172/2155-9562.S9-001

Copyright: (c) 2012 Honeybul S. This is an open-access article distributed under the terms of the Creative Commons Attribution License, which permits unrestricted use, distribution, and reproduction in any medium, provided the original author and source are credited. 
from this perspective the limitations of traditional medical measures such as hyperventilation, barbiturate coma and more recently hypothermia can be appreciated. There is little doubt that barbiturates and hypothermia have the potential to be neuroprotective due to their influence on many mechanisms known to be important in the cellular response to injury such as calcium mediated toxicity, glutamate excitotoxicity, free radical peroxidation and cellular apoptosis [24-27]. However, the often rapid fall in intracranial pressure that occurs after the application of either of these three therapies occurs as a result of cerebral vasoconstriction [28-31]. Given the well known deleterious effects of ischaemia, it perhaps not unsurprising that numerous studies have failed to demonstrate that any of these therapies provide clinical benefit in terms of improvement in long term outcome [28,32-37].

It is here that decompressive craniectomy may have at least a theoretical advantage. By challenging the Monroe Kellie Doctrine and expanding the "rigid box" the intracranial pressure can be reduced but not at the expense of cerebral blood volume and cerebral perfusion appears to be improved [38-40]. What remains to be scientifically established is whether this improvement in cerebral perfusion and oxygenation is converted into clinical benefit.

\section{Clinical Studies}

There have now been numerous publications that have demonstrated the role of decompressive craniectomy in the management of intractable intracranial hypertension following severe traumatic brain injury. However, none of these can be adjudged to have
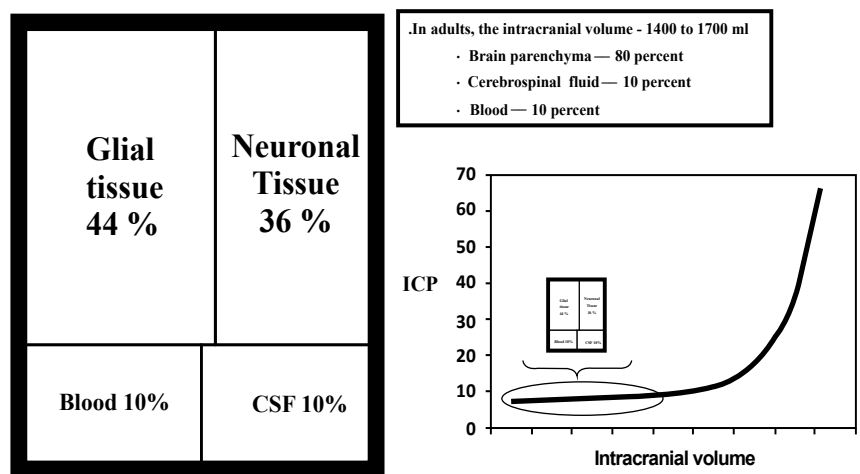

Intracranial volume

Figure 1: The Monroe Kellie Doctrine: In normal physiological circumstances any increase in volume of the constituent components of the intracranial compartment does not cause a significant increase in intracranial pressure (ICP) because of compensatory decrease in volume of either blood or CSF.
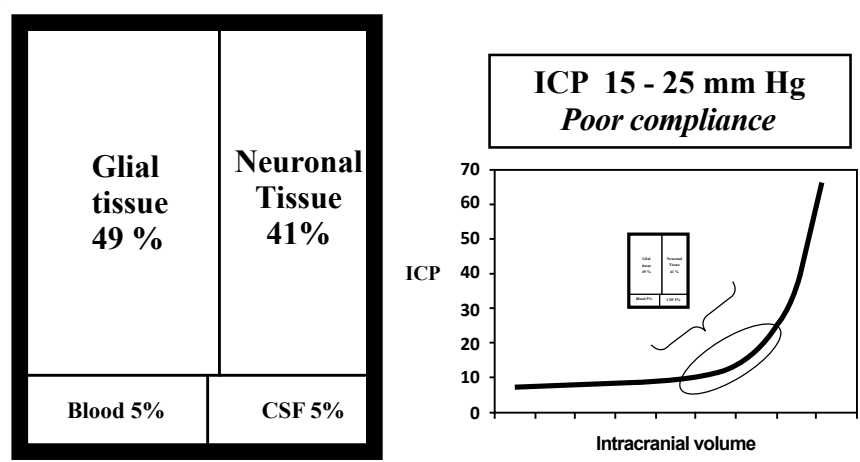

Figure 2: Partially compensated intracranial hypertension: As the brain progressively swells initial compensation is at the expense of blood and CSF.
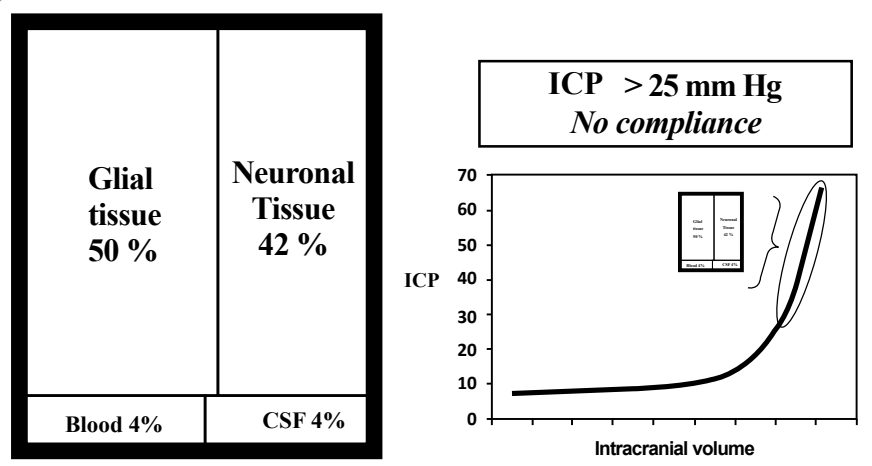

Figure 3: Decompensated intracranial hypertension: As the cerebral swelling worsens or a mass lesion enlarges there comes a point when the compensatory mechanisms start to fail and for smaller increases in swelling there are incrementally greater increases in intracranial pressure.

provided class 1 evidence on which to base clinical practice.

\section{The DECRA study - clinical findings}

The DECRA study is the first randomised controlled trial for adult patients with severe TBI and as such represents the only highlevel evidence pertaining to the surgical management of this group of patients. The trial compared early decompressive craniectomy for diffuse traumatic brain injury with standard medical therapy [7]. The results of the trial were that the patients undergoing craniectomy had lower intracranial pressures (ICP) and spent less time in intensive care, however at six month follow up 51 (70\%) of patients in the craniectomy group has an unfavourable outcome compared with 42 (51\%) of patients in the standard care group ( $\mathrm{OR}=2.21$ [95\% CI: 1.14-4.26] $\mathrm{p}=0.02$ ). Based on these findings the authors concluded that not only was the use of decompressive craniectomy associated with more unfavourable outcomes, but also that by using standard medical therapy rather than surgical decompression, healthcare systems would save millions of dollars per year [41]. Unfortunately these conclusions have not been shared by the global community and overall the observations regarding the trial have been fairly critical [42-45].

\section{The DECRA study - critical appraisal}

In general the debate has centred around three issues $[46,47]$. In the first instance there were some problems with randomisation such that the patients in the surgical arm of the trial had sustained a slightly more severe primary brain injury. More patients in the surgical group had bilateral non-reactive pupils ( $27 \%$ versus $12 \%$; $\mathrm{p}=0.04$ ), radiological findings as adjudged by the Marshall grading were more severe (grade III \& non-evacuated haematoma: total $77 \%$ versus $67 \%$ ) and the GCS was lower (median 5 versus 6). All these factors are significant prognostically and when the pupil reactivity was adjusted for in the multivariate analysis, there was no statistically significant difference between the two groups. Whilst in isolation the differences in radiological findings and GCS fail to reach univariate statistical significance the cumulative affect of these adverse presentation variables mean that the surgical group had a significantly more severe primary brain injuries. Secondly, there was a significant crossover of patients such that $19(23 \%)$ patients in the medical arm had a surgical decompression. Finally there was criticism regarding the relatively low ICP for a relatively short time period that was used as the clinical indicator for surgical decompression and this meant that was that the patients enrolled into the study were not representative of current 
clinical practice $[44,48,49]$.

Based on these observations the overall global response has been fairly critical, indeed some commentators have gone so far as to state that "no conclusions regarding management of the use of decompressive craniectomy in patients with traumatic brain injury should be drawn from this trial and clinical practice should not be changed on the basis of these results" [44]. However, it may be a little premature and certainly a little unfair to adopt a diametrically opposite position and disregard the trial entirely. An alternative approach would be to objectively analyse the results in order to obtain information that can be clinically useful. This raises the following issues that require careful consideration:

The trial hypothesis: In the first instance it must be recognised that this was a well organised, multicentre study, based on genuine clinical equipoise. The trial hypothesis was that early decompressive surgery would lower the intracranial pressure and prevent secondary brain injury. At the time of the trial inception a number of a number of observational clinical studies had shown that in the context of intracranial hypertension surgical decompression could successfully lower ICP $[3,4]$. In addition there had been considerable advances in the understanding of the complex cellular response to trauma and it was becoming progressively more apparent that a substantial amount of cell death is due to a series of deleterious neurochemical cascades that are initiated either at the time of injury or fairly soon thereafter and these can be amplified by secondary insults such as cerebral ischaemia [50,51]. Based on these observations it would appear perfectly reasonable to perform an early decompression in order to limit secondary brain injury.

Timing of surgical decompression: What trial has clearly demonstrated is that an ICP $>20 \mathrm{mmHg}$ for 15 minutes provides insufficient evidence that there are significant ongoing secondary insults and therefore any benefit conferred by decompression is offset by surgical morbidity. This finding would appear to be unequivocal. Whilst there may be some confounding of the results introduced by some problems with randomisation of patients and crossover between the surgical and standard care arms, it has to be accepted that the current scientific evidence is that early surgical decompression in these particular circumstances does not improve outcome. The observation that to perform a decompressive craniectomy in these circumstances is not representative of the current clinical practice is not unreasonable [42-44,49]. However, it should perhaps be acknowledged that the aim of the trial was not to confirm the efficacy of current practice but rather to change that practice. If the trial had confirmed that early decompression provided benefit then although the indication for decompression in the trial was not representative of current clinical practice, the patients in the trial would in fact come to represent the clinical practice of the future. This would have had significant impact on neurosurgical practice and resources.

Why did early decompression provide no benefit?: The question remains as to why the trial failed to show benefit and this must be attributed to surgical morbidity [52-54]. Whilst technically straight forward it is becoming increasingly apparent that there are significant complications associated not only with the decompressive craniectomy but also with the subsequent cranioplasty $[52,55,56]$. These include, hernation of the cerebral cortex through the cranial defect, subdural effusion, hydrocephalus, syndrome of the trephined and infection. Given the high incidence of complications that have been reported it is perhaps not entirely unsurprising that patients in the surgical arm of the trial had a worse outcome than those patients who had relatively mild and transient intracranial hypertension that in most cases was managed adequately with standard medical care. What remains to be established is if what point does any benefit provided by surgical decompression outweigh the morbidity of the approach.

\section{The Future of Decompressive Craniectomy in the Management of Severe TBI}

\section{Advances in multimodal monitoring}

As demonstrated by the DECRA study, using the ICP as an independent indicator of secondary brain injury has some limitations and over recent years a number of multimodal monitoring techniques have been developed such that it is now possible to obtain continuous data regarding a number of physiological and biochemical parameters. The aim of these monitors is to gather as much information as possible in order to assess the severity of secondary insults and there a number of modalities available, the most common being cerebral oxygenation monitoring [57-59] microdialysis [60,61] and continuous EEG monitoring $[62,63]$. Whilst there continues to be debate regarding the precise role of each type of monitor it is becomingly increasingly apparent is that information obtained from a single modality that is interpreted independently from other physiological and metabolic parameters is unlikely to provide significant clinical benefit [64]. Over the next few years there are likely to be further advances in real time data analysis which integrates information gained from a number of parameters and presents it in a clinically user friendly fashion such that a more accurate assessment of secondary brain injury is provided [64]. This can then be used to guide appropriately targeted therapeutic intervention such as surgical decompression.

\section{Ongoing clinical trials}

The role of decompressive surgery as a life saving procedure for those patients who's ICP continues to rise beyond $25 \mathrm{mmHg}$ is currently being addressed by the RESCUEicp (Randomised Evaluation of Surgery with Craniectomy for Uncontrollable Elevation of Intra-Cranial Pressure) trial [65]. Notwithstanding the outcome of this trial the interpretation of any study attempting to demonstrate an improvement in outcome over and above standard medical therapy must be tempered with the realisation that in most centres a decompressive craniectomy is carried out once all medical therapy has either failed or is in the process of failing and the patient is though, unlikely to survive without surgical intervention. In these circumstances attempting to scientifically establish that a decompressive craniectomy provides clinical benefit may be extremely difficult. Once a patient is adjudged to have failed medical therapy can they realistically be randomised to continue that therapy?

\section{Ethical considerations}

A final consideration is long term outcome following decompressive surgery. Whilst a significant number of patients survive following surgery and go on to make a good functional recovery, a significant number remain severely disabled. To what degree that outcome is acceptable to those individuals is difficult to determine however a recent analysis of the patients who had survived having had a decompressive hemicraniectomy for ischaemic stroke found that those patients that had a severely reduced functional status would not have provided consent for the procedure if they had known their eventual outcome [66]. Currently this issue has not been addressed for those patients that survive following TBI however, there has to come a point where 
the primary brain injury is so severe that if a patient survives the most likely long term outcome is one of severe neurological disability [67].

\section{Outcome prediction}

Until recently the difficulty has always been how to accurately assess the severity of the primary brain injury and thereby deciding at what point serious consideration must be given to this issues. However, the CRASH collaborators (corticosteroid randomization after significant head injury) web based outcome prediction model has gone some way to addressing this problem [68]. The model is based on the data obtained from the CRASH study that investigated whether steroids would improve outcome following TBI [69]. Whilst the results of the trial were negative, the significant amount of clinical data enabled the investigators to develop a prediction model incorporating those factors such as; age, initial GCS, pupil reactivity, extracranial injuries and radiological appearances, that are known to have prognostic significance [70-72].

The model provides a percentage predicted risk of unfavourable outcome at six months (defined by the Glasgow Outcome Scale as; dead, persistent vegetative state or severely disabled [73]. Previous studies have demonstrated how the predicted risk can be used as a surrogate index of injury severity $[74,75]$. These studies compared the percentage predicted risk of an unfavourable outcome with the observed long term outcome in a cohort of patients who had had a decompressive craniectomy following severe traumatic brain injury. It can be seen from Figure 4 how the predicted risk can be used to stratify patients according to injury severity and this can be used as an objective assessment of the most likely long term outcome following decompressive surgery. For example, it can be seen from these results that once the percentage risk of unfavourable outcome is greater than $80 \%$, the observed long term outcome for those patients that survive is one of severe disability.

\section{Clinical Applications of Outcome Prediction Models}

The applications of this type of objective assessment have yet to be explored however a number of small studies have demonstrated how this type of information could influence clinicians opinion when considering what may be considered life saving but none restorative surgical intervention $[76,77]$. In addition, whilst we fully agree with the CRASH collaborators that the this model should only be used to support and not replace clinical judgement, it could provide supportive

\section{$\square$ Good $\square$ Moderate 固 Sereve $\square$ Vegetative $\square$ Dead}

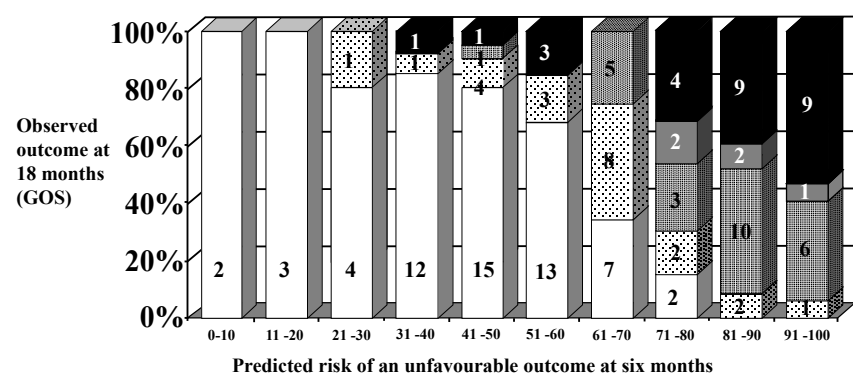

Figure 4: Stratification of patients according to injury severity: The prediction of an unfavourable outcome at six months ( $x$ axis) and the observed outcome at eighteen months among the 137 patients on whom 18 month follow up was available. Numbers within the bar chart represent absolute patient numbers. (Reproduced with kind permission Mary Ann Liebert, Inc. publishers). information which could be used to facilitate the discussion of realistic outcome expectations.

\section{Conclusions}

The current role of decompressive craniectomy in the management of severe traumatic brain injury has yet to be established. The results of the recent DECRA have provided important clinical information and demonstrated some of the difficulties encountered when planning and executing trials of this nature. Whilst the results may not significantly alter the current neurosurgical practice the trial has in some ways suggested that more surgical judgement may be required prior to considering surgical decompression because in certain situations it may provide no benefit and may in fact do more harm. Prior to the findings of the study it was almost assumed that lowering the intracranial pressure by surgical decompression would be beneficial and whilst many authorities remain convinced of clinical efficacy it has to be accepted that this remains scientifically unproven.

\section{References}

1. Aarabi B, Hesdorffer DC, Ahn ES, Aresco C, Scalea TM, et al. (2006) Outcome following decompressive craniectomy for malignant swelling due to severe head injury. J Neurosurg 104: 469-479.

2. Albanèse $J$, Leone $M$, Alliez JR, Kaya JM, Antonini $F$, et al. (2003) Decompressive craniectomy for severe traumatic brain injury: Evaluation of the effects at one year. Crit Care Med 31: 2535-2538.

3. Münch E, Horn P, Schürer L, Piepgras A, Paul T, et al. (2000) Management of severe traumatic brain injury by decompressive craniectomy. Neurosurgery 47: 315-322.

4. Polin RS, Shaffrey ME, Bogaev CA, Tisdale N, Germanson T, et al. (1997) Decompressive bifrontal craniectomy in the treatment of severe refractory posttraumatic cerebral edema. Neurosurgery 41: 84-92.

5. Juul N, Morris GF, Marshall SB, Marshall LF (2000) Intracranial hypertension and cerebral perfusion pressure: influence on neurological deterioration and outcome in severe head injury. The Executive Committee of the International Selfotel Trial. J Neurosurg 92: 1-6.

6. Marmarou A, Anderson R, Ward JD (1991) Impact of ICP instability and hypotension on outcome in patients with severe head trauma. J Neurosurg 75: s59-s66.

7. Cooper DJ, Rosenfeld JV, Murray L, Arabi YM, Davies AR, et al. (2011) Decompressive craniectomy in diffuse traumatic brain injury. $\mathrm{N}$ Engl $\mathrm{J}$ Med 364: 1493-1502.

8. Cooper PR, Rovit RL, Ransohoff J (1976) Hemicraniectomy in the treatment of acute subdural hematoma: a re-appraisal. Surg Neurol 5: 25-28.

9. Ransohoff J, Benjamin $\vee(1971)$ Hemicraniectomy in the treatment of acute subdural haematoma. J Neurol Neurosurg Psychiatry 34: 106.

10. Cooper PR, Hagler H, Clark WK, Barnett P (1979) Enhancement of experimental cerebral edema after decompressive craniectomy: implications for the management of severe head injuries. Neurosurgery 4: 296-300.

11. Hofmeijer J, Kappelle LJ, Algra A, Amelink GJ, van Gijn J, et al. (2009) HAMLET investigators. Surgical decompression for space-occupying cerebral infarction (the Hemicraniectomy After Middle Cerebral Artery infarction with Life-threatening Edema Trial [HAMLET]): a multicentre, open, randomised trial. Lancet Neurol 8: 326-333.

12. Jüttler E, Schwab S, Schmiedek P, Unterberg A, Hennerici M, et al. (2007) Decompressive Surgery for the Treatment of Malignant Infarction of the Middle Cerebral Artery (DESTINY): a randomized, controlled trial. Stroke 38: 25182525.

13. Vahedi K, Vicaut E, Mateo J, Kurtz A, Orabi M, et al. (2007) Sequential-design, multicenter, randomized, controlled trial of early decompressive craniectomy in malignant middle cerebral artery infarction (DECIMAL Trial). Stroke 38: 25062517.

14. Fisher CM, Ojemann RG (1994) Bilateral decompressive craniectomy for worsening coma in acute subarachnoid hemorrhage. Observations in support of the procedure. Surg Neurol 41: 65-74. 
Citation: Honeybul S (2012) Decompressive Craniectomy for Severe Traumatic Brain Injury: A Review of its Current Status. J Neurol Neurophysiol S9. doi:10.4172/2155-9562.S9-001

Page 5 of 6

15. Smith ER, Carter BS, Ogilvy CS (2002) Proposed use of prophylactic decompressive craniectomy in poor-grade aneurysmal subarachnoid hemorrhage patients presenting with associated large sylvian hematomas. Neurosurgery 51: 117-124.

16. Baussart B, Cheisson G, Compain M, Leblanc PE, Tadie M, et al. (2006) Multimodal cerebral monitoring and decompressive surgery for the treatment of severe bacterial meningitis with increased intracranial pressure. Acta Anaesthesiol Scand 50: 762-765

17. Di Rienzo A, lacoangeli M, Rychlicki F, Veccia S, Scerrati M (2008) Decompressive craniectomy for medically refractory intracranial hypertension due to meningoencephalitis: report of three patients. Acta Neurochir (Wien) 150: 1057-1065.

18. González Rabelino GA, Fons C, Rey A, Roussos I, Campistol J (2008) Craniectomy in herpetic encephalitis. Pediatr Neurol 39: 201-203.

19. Perin A, Nascimben E, Longatti $P$ (2008) Decompressive craniectomy in a case of intractable intracranial hypertension due to pneumococcal meningitis. Acta Neurochir (Wien) 150: 837-842.

20. Plesnila N (2007) Decompression craniectomy after traumatic brain injury: recent experimental results. Prog Brain Res 161: 393-400.

21. Zweckberger K, Erös C, Zimmermann R, Kim SW, Engel D, et al. (2006) Effect of early and delayed decompressive craniectomy on secondary brain damage after controlled cortical impact in mice. J Neurotrauma 23: 1083-1093.

22. Monroe $\mathrm{J}$ (1783) Observationson the structures and functions of the nervous system. Edinburgh. W Creech.

23. Kellie G (1824) An account with some reflections on the pathology of the brain. Edinburgh Med Chir Soc Trans.

24. Koerner IP, Brambrink AM (2006) Brain protection by anesthetic agents. Curr Opin Anaesthesiol 19: 481-486.

25. Koizumi H, Povlishock JT (1998) Posttraumatic hypothermia in the treatment of axonal damage in an animal model of traumatic axonal injury. $J$ Neurosurg 89: 303-309.

26. Sahuquillo J, Vilalta A (2007) Cooling the injured brain: how does moderate hypothermia influence the pathophysiology of traumatic brain injury. Curr Pharm Des 13: 2310-2322.

27. Sutcliffe IT, Smith HA, Stanimirovic D, Hutchison JS (2001) Effects of moderate hypothermia on IL-1 beta-induced leukocyte rolling and adhesion in pial microcirculation of mice and on proinflammatory gene expression in human cerebral endothelial cells. J Cereb Blood Flow Metab 21: 1310-1319.

28. Curley G, Kavanagh BP, Laffey JG (2010) Hypocapnia and the injured brain: more harm than benefit. Crit Care Med 38: 1348-1359.

29. Kassell NF, Hitchon PW, Gerk MK, Sokoll MD, Hill TR (1980) Alterations in cerebral blood flow, oxygen metabolism, and electrical activity produced by high dose sodium thiopental. Neurosurgery 7: 598-603.

30. Nordström CH, Messeter K, Sundbärg G, Schalén W, Werner M, et al. (1988) Cerebral blood flow, vasoreactivity, and oxygen consumption during barbiturate therapy in severe traumatic brain lesions. J Neurosurg 68: 424-431.

31. Yundt KD, Diringer MN (1997) The use of hyperventilation and its impact on cerebral ischemia in the treatment of traumatic brain injury. Crit Care Clin 13 163-184

32. Clifton GL, Miller ER, Choi SC, Levin HS, McCauley S, et al. (2001) Lack of effect of induction of hypothermia after acute brain injury. N Engl J Med 344: 556-563.

33. Clifton GL, Valadka A, Zygun D, Coffey CS, Drever P, et al. (2011) Very early hypothermia induction in patients with severe brain injury (the National Acute Brain Injury Study: Hypothermia II): a randomised trial. Lancet Neurol 10: 131139.

34. Eisenberg HM, Frankowski RF, Contant CF, Marshall LF, Walker MD (1988) High-dose barbiturate control of elevated intracranial pressure in patients with severe head injury. J Neurosurg 69: 15-23.

35. Hutchison JS, Ward RE, Lacroix J, Hébert PC, Barnes MA, et al. (2008) Hypothermia therapy after traumatic brain injury in children. N Engl J Med 358 2447-2456.

36. Muizelaar JP, Marmarou A, Ward JD, Kontos HA, Choi SC, et al. (1991) Adverse effects of prolonged hyperventilation in patients with severe head injury: a randomized clinical trial. J Neurosurg 75: 731-739.

37. Ward JD, Becker DP, Miller JD, Choi SC, Marmarou A, et al. (1985) Failure of prophylactic barbiturate coma in the treatment of severe head injury. $J$ Neurosurg 62: 383-388.

38. Ho CL, Wang CM, Lee KK, Ng I, Ang BT (2008) Cerebral oxygenation, vascular reactivity, and neurochemistry following decompressive craniectomy for severe traumatic brain injury. J Neurosurg 108: 943-949.

39. Jaeger M, Soehle M, Meixensberger J (2003) Effects of decompressive craniectomy on brain tissue oxygen in patients with intracranial hypertension. $J$ Neurol Neurosurg Psychiatry 74: 513-515.

40. Yamakami I, Yamaura A (1993) Effects of decompressive craniectomy on regional cerebral blood flow in severe head trauma patients. Neurol Med Chir (Tokyo) 33: 616-620.

41. Cooper DJ, Rosenfeld JV (2011) Does decompressive craniectomy improve outcomes in patients with diffuse traumatic brain injury? Med J Aust 194: 437438 .

42. Komotar RJ, Starke RM, Connolly ES (2011) The role of decompressive craniectomy in diffuse traumatic brain injury. Neurosurgery 69: N22-24.

43. Simard JM, Kahle KT, Walcott BP (2011) Craniectomy in diffuse traumatic brain injury. N Engl J Med 365: 374.

44. Timmons SD, Ullman JS, Eisenberg HM (2011) Craniectomy in diffuse traumatic brain injury. N Engl J Med 365: 373.

45. Vashu R, Sohail A (2011) Decompressive craniectomy is indispensible in the management of severe traumatic brain injury. Acta Neurochir (Wien) 153 2065-2066.

46. Honeybul S, Ho KM, Lind CR, Gillett GR (2011) Decompressive craniectomy for diffuse cerebral swelling after trauma: long-term outcome and ethical considerations. J Trauma 71: 128-132.

47. Honeybul S, Ho KM, Lind CR, Gillett GR (2011) The future of decompressive craniectomy for diffuse traumatic brain injury. J Neurotrauma 28: 2199-2200.

48. Hutchinson PJ, Timofeev I, Kolias AG, Corteen EA, Czosnyka M, et al. (2011) Decompressive craniectomy for traumatic brain injury: the jury is still out. $\mathrm{Br}$ Neurosurg 25: 441-442.

49. Servadei $F$ (2011) Clinical value of decompressive craniectomy. N Engl J Med 364: 1558-1559.

50. Bullock R (1993) Pathophysiological alterations in the central nervous system due to trauma. Schweiz Med Wochenschr 123: 449-458.

51. Sahuquillo J, Poca MA, Amoros S (2001) Current aspects of pathophysiology and cell dysfunction after severe head injury. Curr Pharm Des 7: 1475-1503.

52. Honeybul S, Ho KM (2011) Long-term complications of decompressive craniectomy for head injury. J Neurotrauma 28: 929-935.

53. Stiver SI (2009) Complications of decompressive craniectomy for traumatic brain injury. Neurosurg Focus 26: E7.

54. Yang XF, Wen L, Shen F, Li G, Lou R, et al. (2008) Surgical complications secondary to decompressive craniectomy in patients with a head injury: a series of 108 consecutive cases. Acta Neurochir (Wien) 150: 1241-1247.

55. Gooch MR, Gin GE, Kenning TJ, German JW (2009) Complications of cranioplasty following decompressive craniectomy: analysis of 62 cases. Neurosurg Focus 26: E9.

56. Honeybul S (2011) Sudden death following cranioplasty: a complication of decompressive craniectomy for head injury. Br J Neurosurg 25: 343-345.

57. Narotam PK, Morrison JF, Nathoo N (2009) Brain tissue oxygen monitoring in traumatic brain injury and major trauma: outcome analysis of a brain tissue oxygen-directed therapy. J Neurosurg 111: 672-682.

58. Stiefel MF, Spiotta A, Gracias VH, Garuffe AM, Guillamondegui O, et al. (2005) Reduced mortality rate in patients with severe traumatic brain injury treated with brain tissue oxygen monitoring. J Neurosurg 103: 805-811.

59. Martini RP, Deem S, Yanez ND, Chesnut RM, Weiss NS, et al. (2009) Management guided by brain tissue oxygen monitoring and outcome following severe traumatic brain injury. J Neurosurg 111: 644-649.

60. Nelson DW, Thornquist B, MacCallum RM, Nyström H, Holst A, et al. (2011) Analyses of cerebral microdialysis in patients with traumatic brain injury: 
Citation: Honeybul S (2012) Decompressive Craniectomy for Severe Traumatic Brain Injury: A Review of its Current Status. J Neurol Neurophysiol S9. doi:10.4172/2155-9562.S9-001

Page 6 of 6

relations to intracranial pressure, cerebral perfusion pressure and catheter placement. BMC Med 9: 21

61. Johnston AJ, Gupta AK (2002) Advanced monitoring in the neurology intensive care unit: microdialysis. Curr Opin Crit Care 8: 121-127.

62. Vespa PM, Nuwer MR, Nenov V, Ronne-Engstrom E, Hovda DA, et al. (1999) Increased incidence and impact of nonconvulsive and convulsive seizures after traumatic brain injury as detected by continuous electroencephalographic monitoring. J Neurosurg 91: 750-760.

63. Vespa PM, Boscardin WJ, Hovda DA, McArthur DL, Nuwer MR, et al. (2002) Early and persistent impaired percent alpha variability on continuous electroencephalography monitoring as predictive of poor outcome after traumatic brain injury. J Neurosurg 97: 84-92.

64. Diedler J, Czosnyka M (2010) Merits and pitfalls of multimodality brain monitoring. Neurocrit Care 12: 313-316.

65. Hutchinson PJ, Corteen E, Czosnyka M, Mendelow AD, Menon DK, et al. (2006) Decompressive craniectomy in traumatic brain injury: the randomized multicenter RESCUEicp study (www.RESCUEicp.com). Acta Neurochir Suppl 96: 17-20.

66. Kiphuth IC, Köhrmann M, Lichy C, Schwab S, Huttner HB (2010) Hemicraniectomy for malignant middle cerebral artery infarction: retrospective consent to decompressive surgery depends on functional long-term outcome. Neurocrit Care 13: 380-384

67. Gillett GR, Honeybul S, Ho KM, Lind CR (2010) Neurotrauma and the RUB where tragedy meets ethics and science. J Med Ethics 36: 727-730.

68. MRC CRASH Trial Collaborators, Perel P, Arango M, Clayton T, Edwards P, et al. (2008) Predicting outcome after traumatic brain injury: practical prognostic models based on large cohort of international patients. BMJ 336: 425-429.

69. Roberts I, Yates D, Sandercock P, Farrell B, Wassenberg J, et al. (2004) Effect of intravenous corticosteroids on death within 14 days in 10008 adults with clinically significant head injury (MRC CRASH trial): randomised placebocontrolled trial. Lancet 364: 1321-1328.

70. Cremer OL, Moons KG, van Dijk GW, van Balen P, Kalkman CJ (2006) Prognosis following severe head injury: Development and validation of a model for prediction of death, disability, and functional recovery. J Trauma 61: 1484 1491

71. Meier U, Gräwe A, König A (2005) The importance of major extracranial injuries by the decompressive craniectomy in severe head injuries. Acta Neurochir Suppl 95: 55-57.

72. Steyerberg EW, Mushkudiani N, Perel P, Butcher I, Lu J, et al. (2008) Predicting outcome after traumatic brain injury: development and international validation of prognostic scores based on admission characteristics. PLoS Med 5: e165.

73. Jennett B, Bond M (1975) Assessment of outcome after severe brain damage. Lancet 1: 480-484.

74. Honeybul S, Ho KM, Lind CR, Corcoran T, Gillett GR (2009) The retrospective application of a prediction model to patients who have had a decompressive craniectomy for trauma. J Neurotrauma 26: 2179-2183.

75. Honeybul S, Ho KM, Lind CR, Gillett GR (2010) Observed versus predicted outcome for decompressive craniectomy: a population-based study. J Neurotrauma 27: 1225-1232

76. Honeybul S, O'Hanlon S, Ho KM (2011) Decompressive craniectomy for severe head injury: does an outcome prediction model influence clinical decisionmaking? J Neurotrauma 28: 13-19.

77. Honeybul S, O'Hanlon S, Ho KM, Gillett G (2011) The influence of objective prognostic information on the likelihood of informed consent for decompressive craniectomy: a study of Australian anaesthetists. Anaesth Intensive Care 39: 659-665.

This article was originally published in a special issue, Traumatic Brain Injury: Diagnosis \& Treatment handled by Editor(s). Dr. Douglas Mckay Wallace, University of Miami, USA 